\title{
Aesthetic Virtues: Traits and Faculties
}

\author{
Penultimate Draft - please cite published version.
}

\begin{abstract}
Two varieties of aesthetic virtue are distinguished. Trait virtues are features of the agent's character, and reflect an overarching concern for aesthetic goods such as beauty and novelty, while faculty virtues are excellences of artistic execution that permit the agent to succeed in her chosen domain. The distinction makes possible a fuller account of why art matters to us - it matters not only insofar as it is aesthetically good, but also in its capacity as an achievement that is creditable to an individual, and as a reflection or embodiment of virtuous motives.
\end{abstract}

\section{Introduction}

A virtue theory of aesthetics places a special emphasis upon the artist and her character traits, skills, dispositions and motivations (Goldie 2007, 2008, 2010; Kieran 2010, 2012; Lopes 2008; Woodruff 2001). It aims to encourage a redirection of philosophical attention, such that the primary objects of aesthetic enquiry and evaluation are taken to include not only art objects, but also artistic activities of creation, performance, and appreciation. Just as virtue ethics holds that moral evaluation properly targets the person and the qualities of her character, as well as her actions, so the virtue theory of art recommends a focus on the ways in which the agent's aesthetic virtues and vices are manifested in practises of artmaking and art-appreciation. Aesthetic evaluation is appropriately directed not only at the products of artistic activity - paintings, dances, sculptures and so forth - but at the qualities of the person performing such activities, including her individual virtues and vices.

Construed modestly, the aim of the virtue theory is simply to promote this broadening of the subject matter of philosophical aesthetics: to capture something of interest about the role of creative events, intentions, and behaviours in the production and appreciation of the works of art that form the traditional aesthetic domain. More strongly, the virtue theorist may hold that the aesthetic virtues have a conceptual or explanatory priority 
within the project of defining the nature of art itself, such that artworks are taken necessarily to be the products of virtuous activity suitably understood.

A virtue-oriented approach, moreover, provides novel resources for tackling the question of why art matters to us (as Goldie 2008: 180, has put it). By attending to artistic forms of excellence, as we attend elsewhere to qualities of an individual's moral and intellectual character, we can better understand the value of artworks qua products of aesthetic virtue. For Goldie, the source of this value lies in the contribution of aesthetically virtuous action to human flourishing; specifically, to the rich forms of interpersonal emotional sharing that are afforded by participation in art making and art enjoyment. Art objects are thus thought to be instrumentally good, on this analysis, insofar as they provide opportunities for creative and appreciative virtues to be exercised. An alternative view of the connection between aesthetic virtue and the value of art is presented by Dominic Lopes (2008), who reverses this order of explanation in arguing that the aesthetic virtues inherit a species of intrinsic value from the artworks towards which they are essentially and positively directed. The aesthetic virtues accrue their value from the explanatorily prior value of art itself, for instance the beauty, elegance, or novelty of a creation.

This paper has two aims. Firstly, to carve a taxonomic distinction among types of aesthetic virtue, to provide an account of the psychological and behavioural features of an agent that are to be counted among her aesthetic virtues and vices. Secondly, to use this distinction to argue for two further answers to the question of why artworks that are the products of aesthetic virtue matter to us. I will argue that both issues can be productively informed by drawing closely upon the domain of virtue epistemology, within which detailed analyses of varieties of virtue, and their associated values, have been more fully developed (e.g. Axtell 1997; Battaly 2008; Greco 2000; Sosa 2007; Zagzebski 1996). On the taxonomic question, I exploit a central distinction between two kinds of virtue that has been recognised by epistemologists interested in the intellectual excellences. On the one hand, epistemic virtue responsibilists (e.g. Code 1987; Montmarquet 1993; Zagzebeski 1996) promote a full-blooded conception according to which the virtues involved in successful intellectual enterprise are to be modeled closely upon Aristotelian moral virtues, where paradigm cases include traits of character such as open-mindedness, fairness, and intellectual humility (trait or character virtues). On the 
other hand, epistemic virtue reliabilists (e.g. Greco 2012; Sosa 2007) conceive of intellectual virtues in more deflationary terms, and include cognitive and perceptual faculties such as vision, memory, and reasoning among the knowledge-conducive excellences of the epistemic subject (faculty or ability virtues).

In parallel with the epistemic case, I will argue that two varieties of aesthetic virtue can be distinguished: those that belong to the agent's traits of character and are closely bound up with her patterns of motivation and concern, such as aesthetic honesty, courage, and integrity; and those that pertain to her abilities to successfully achieve some set of aesthetic outcomes, such as technical dexterity with a musical instrument, precision as a draftsperson, or the capacity to execute a dance with grace and economy.

Drawing this distinction allows us to identify two forms of value that accrue to artworks that are the products of the respective varieties of virtue. By focusing on aesthetic faculty virtues - virtues of performance and execution - we can exploit the insights of the achievement account of value, as it is found both in epistemology (e.g. Greco 2003, 2009) and elsewhere in aesthetics (e.g. Huddleston 2012). When an artistic outcome is an achievement that is creditable to a person, due to its being the product of her own aesthetic abilities, it gains a distinctive kind of value, in common with achievements in other domains, such as sporting or intellectual successes. By focusing on aesthetic trait virtues, meanwhile, we can understand works of art as having, or embodying, admirable qualities that flow from the agent's virtuous motivations.

\section{Two varieties of epistemic virtue}

Virtue epistemology tackles questions concerning the nature and value of knowledge by attributing a foundational role to the belief-forming abilities of the doxastic subject, and her status as a virtuous or vicious epistemic agent. When making evaluations concerning the quality of an agent's epistemic condition, we are to privilege the ways in which she comes to acquire and maintain her beliefs over time, and the various skills and intellectual capacities she puts into play during the course of her enquiries.

Virtue epistemologists are divided, however, over how best to conceive of the intellectual virtues. Those in the reliabilist tradition hold that individual cognitive faculties such as 
sharp eyesight, accurate memory, and dependable reasoning skills are relevant forms of epistemic excellence (e.g. Sosa 1991). True beliefs achieve the status of knowledge, on views of this sort, just when they are the products of stable and reliable truth-conducive powers of the agent. Those in the responsibilist tradition, meanwhile, argue that epistemic virtues should be aligned more closely with the full-blooded qualities associated with Aristotelian moral thinking; traits that are appropriately attributed to the agent's cognitive character, such as open-mindedness, intellectual courage, humility, and fairness.

Although there is no need to attempt to legislate between these two varieties of epistemological virtue theory here, it is worth briefly clarifying the primary differences between intellectual virtues construed as faculty excellences and those conceived of as character traits, as it is these details that will be taken up in the course of articulating the aesthetic virtues more comprehensively. In the latter domain, too, the question is whether to treat aesthetic virtues as constituted by faculties and skills deployed by the agent in the course of her artistic endeavours, or to see them as deep and abiding character traits that show up in acts of artistic creation and appreciation.

On the traits approach, epistemic virtues are "deep qualities of a person, closely identified with her selfhood" (Zagzebski 1996: 104). They are stable and enduring excellences belonging to the agent herself, for which she can be appropriately evaluated. The epistemically virtuous person is intellectually honest, charitable, open-minded, courageous, and so forth, where these traits reflect an overarching concern for epistemic goods such as truth and understanding. Epistemic honesty, for instance, involves a willingness to reflect critically upon one's own doxastic commitments, to weigh countervailing evidence fairly, and to change one's mind in the face of new information even when it is unwelcome. Good believers are those who form and maintain their doxastic position according to virtuous dispositions like these, and fail to exemplify epistemic vices such as laziness, self-deception and dogmatism. Traits of this sort are typically understood to be the agent's responsibility, in the sense that she has acquired and cultivated her character over time, such that these properties become engrained and habitual features of her epistemic outlook. 
Trait virtues occupy a certain distinctive relation to the agent's motivational and affective states. The virtuous epistemic subject cares about the truth, and is motivated by a desire to seek it for its own sake. She is not merely disposed to acquire true beliefs, but to be suitably moved by a concern that her doxastic condition accurately depicts the way the world is (rather than to accept what it is popular or easy to believe, say). In Montmarquet's (1993: viii) term, an agent is epistemically conscientious when she has such an attitude of concern for the truth - an attitude that is reflected in individual truthseeking traits such as intellectual honesty or fairness.

The faculties perspective offers a more permissive and deflationary analysis of the epistemic virtues. Any stable contributor to the formation of an agent's beliefs is capable of operating virtuously, including perceptual powers and cognitive capacities. On this view, the measure of epistemic excellence is reliability - an agent has a faculty virtue just when the capacity in question consistently allows her to achieve cognitive contact with the world. Acute hearing, a discriminating palate, or powerful recall are thus all examples of epistemic faculty virtues. These powers may be either acquired or innate; there is no requirement that the subject have invested resources in their cultivation or development. She may simply have an exceptional memory, or especially sensitive sensory mechanisms in some modality, for instance. Thus they need not be features for which the agent rightly deserves special praise or blame; they don't necessarily reflect her evaluative qualities as an individual, and it isn't appropriate to think less of someone for her naturally poor eyesight, for example.

Epistemic faculty virtues also lack a necessary connection to the motivational or affective profile of the agent - someone can be an excellent perceiver or reasoner, say, without her use of these faculties being driven by a particular concern for the truth. Indeed, an epistemically trait-vicious person - who is lazy, dogmatic, or gullible - may nonetheless possess a range of high quality faculties.

\section{Aesthetic traits and faculties}

An analogous distinction may be drawn when taxonomising the aesthetic virtues. To anticipate, I hold that there exist faculty virtues associated with individual forms of artistic expression and performance - including for example excellence in drawing skill; 
perfect pitch; good rhythm; breath control; or the timbre of one's voice - and that there exist more full-blooded trait virtues that can shape and inform artistic endeavour more generally and more deeply, such as aesthetic forms of generosity, honesty, and authenticity.

Firstly, note that we speak evaluatively of varieties of aesthetic excellence that seem to fall naturally into each of these two categories. We say, on the one hand, that a sketcher has excellent draftsmanship, that a dancer has grace and balance, that a singer has an impressive vocal range, and so forth. And on the other hand, we speak of a playwright's courage, a poet's honesty, and a novelist's integrity. We are happy to attribute to a portrait painter a combination of both the excellences of accuracy and steadyhandedness, and the virtues associated with producing a sympathetic but not dishonestly flattering likeness of her sitter (Goldie 2008:189). Folk talk concerning aesthetic quality thus makes ready use of two kinds of vocabulary when it comes to describing individual agents, the former category bearing the hallmarks of faculty virtue, and the latter those of trait virtue.

\subsection{Aesthetic trait virtues}

Aesthetic trait virtues again fit the Aristotelian model in being deep and abiding features of an agent that are fully implicated in her personal identity and our evaluation thereof (Goldie 2007, 2008). ${ }^{1}$ In parallel to the epistemic case, we can analyse the aesthetic trait virtues in terms of the aesthetically conscientious agent's possession of an overarching concern for the aesthetically good - the beautiful, the elegant, the funny, the novel, the conceptually provocative, and so forth. The aesthetically virtuous person is one whose traits of character reflect a commitment to the promotion and appreciation of these goods; not merely through being dispositions to act in characteristic ways, but by constituting engrained patterns of care, affect and motivation. The trait-virtuous agent is one who is moved to act in certain ways, to be driven by desires that reflect her evaluative take on matters of aesthetic concern, and to feel appropriate sorts of emotional response to aesthetically relevant situations.

\footnotetext{
${ }^{1}$ Goldie's treatment of aesthetic virtue is explicitly Aristotelian in character, but he also describes "being a good composer, sculptor, or painter" (2010: 832) as a virtue, and this falls more naturally into the second category, that of faculty virtue.
} 
Consider, for example, the virtue of aesthetic courage. In a novelist or painter, say, this trait involves being moved to face and overcome various challenges of subject matter and execution; to take risks; and to resist the temptation to retreat to safe aesthetic ground. The courageous author is not afraid to explore the boundaries of structure and form; to use her writing to expose uncomfortable truths; or to transgress societal taboos; and nor is she swayed by fear of the critical disapprobation of her peers. Secondly, an agent is aesthetically bonest when she exhibits the kinds of feature that indicate credibility or integrity as an artist: for example by creating art that reveals her perspective on matters that are deeply personal, or that will make her unpopular. The trait of honesty is exhibited, too, by the portrait painter whose depictions are faithful and revealing without being unduly swayed by the desire to please her subject. The courageous artist is undeterred by the challenges she faces while pursuing her aesthetic ends; while the honest artist does not compromise her pursuit of these ends by being pulled towards the popular or the profitable. The aesthetic trait virtues are those that empower one to see through the challenging business of creating and appreciating art, including discipline, diligence, focus, enthusiasm, carefulness, patience and thoroughness.

In contrast, the aesthetic trait vices are characterised by a lack of appropriate concern for the aesthetically good, and a tendency to be driven by competing motives - such as a desire for prestige, wealth, or approval. The aesthetically lazy, dishonest, or cowardly individual, that is, is too willing to set aside her concern for the beautiful (etc) and is instead swayed by external incentives. If a songwriter produces a catalogue of formulaic, homogenous melodies because she knows they will sell well, she is guilty of laziness and avarice, while the curator who refuses to display anything but the most rarefied or inaccessible material can be accused of narrow-mindedness or snobbery (Kieran 2010).

In the doxastic case, a simple desire for the truth does not always suffice for epistemic conscientiousness, for an agent can possess such a desire while still suffering from intellectual vices such as dogmatism or fanaticism (Montmarquet 1993). These failings involve a single-minded fixation on a narrow set of ideas, at the expense of countervailing evidence or opinion. In Montmarquet's view, true epistemic excellence involves the exercise of 'regulative' virtues - traits that ensure that the desire for truth is appropriately expressed in thought and action. Once again, the same is true of the aesthetic trait virtues. It is not enough that an agent have an overriding desire for the 
aesthetically good - for this is consistent with her having a vice of excess such as an obsessive attachment to a single artistic genre. The aesthetically conscientious person must thus be equipped with regulatory virtues suitable for the promotion of aesthetic goods; for instance, an open-minded receptivity to possible sources of aesthetic value, or the tenacity and ambition to engage with unfamiliar techniques or genres.

The aesthetic trait virtues are the responsibility of the agent who possesses them - they are features for which she can be held accountable, and which go some way towards constituting her character as a person. This is due, firstly, to the fact that such traits are under the subject's voluntary control and, secondly, because they reveal some of the core principles to which she is evaluatively committed. As Zagzebski has put it for the case of the moral excellences, "it is part of the nature of virtue... that it is the result of moral work on the part of the human agent, and that it be acquired by a process of habituation" (1996: 125). Being an honest or generous artist, for instance, is a status for which an individual can take responsibility over time, through developing proper habits and cultivating practical wisdom. Because the trait virtues are potentially accessible to (almost) everyone, we can place legitimate expectations on persons to ensure that they take steps to shape their characters appropriately - they are "qualities that deserve praise for their presence and blame for their absence" (op cit: 104).

Moreover, an agent's trait virtues disclose her cares and concerns - in this case, her take on the importance of various aesthetic goods - and so constitute an element of her personhood for which she is answerable (see, e.g., Smith 2005). We can ask her to defend, explain, and justify her position, and expect to receive a response that rationally reflects a consistent evaluative perspective. A virtuous critic, for instance, can be expected to offer reasons for her value judgements, just as a good epistemic subject can provide reasons that justify the beliefs she holds.

One kind of answer to the question of what makes a virtuous artist or appreciator, then, appeals to the individual's quality as a person; to trait virtues that sit alongside moral and epistemic excellences in defining the agent's character, and which can be cultivated and refined over time. However, this way of formulating the aesthetic virtues makes no reference to the peculiar skills and talents of individual artists, performers, or critics. Indeed, the possession of the aesthetic trait virtues, as so far conceived, is consistent with 
a total absence of artistic ability or merit, and the presence of - for example - a tuneless singing voice, poor rhythm, childlike drawing skills, or clumsy execution on the piano. In the next section, therefore, I defend a second category of aesthetic virtue whose defining features mirror those of the epistemic faculty virtues, and which characterise the qualities held by an artist or critic who is an excellent performer in their chosen domain.

\subsection{Aesthetic faculty virtues}

Aesthetic faculties can be understood, in this context, as the broad class of relatively stable powers of the agent that contribute to her execution of some artistic activity, such as music-making, painting, or sculpture. I will not attempt a definition of artistic activity here, but will rely on an appeal to familiar cases in which an individual participates in some creative performance the primary end of which is an aesthetic good such as beauty and its appreciation. Those faculties that are associated with guitar playing, for instance, include shaping and gripping of the fingers, picking and strumming, tuning, and timekeeping. Those implicated in watercolour painting include composition, colour mixing, brushstroke technique, blotting, and washing.

In the epistemic case, we saw that faculty excellence is measured in terms of reliability: the extent to which some mechanism is a successful, steady contributor to the agent's stock of true beliefs. There is an analogous sense in which aesthetic faculty virtue can be expressed in reliabilist terms, too. A subject possesses the virtue of reliability in respect of her aesthetic faculties when they enable her to achieve repeatable success in some artistic domain. A reliable pianist plays the right keys, follows the dynamics of the piece, and keeps time. A reliable singer stays in tune, controls her breathing, and remembers the lyrics. The notion of reliability at issue here, then, is one of technical facility - having and exercising a suite of competencies that enable the artist to execute her aesthetic aims.

This is the sense of virtue at play when we say of someone that they draw well, or that they are a good violinist, and mean that they have a fine degree of technical proficiency in that discipline. The attribution implies that the agent's achievement is not a one-off, and that they have a stable power to replicate a range of similar successes under ordinary circumstances. And it implies at least a degree of versatility - we are inclined to withhold 
the attribution of good musician or even of good pianist when faced with someone who can play only one piece of music on the instrument, for instance, however well they do so.

The question of what it is for an agent to have the power to perform artistic activities well is not to be answered by appeal only to the technical achievements associated with the successful completion of some artistic output, however. Indeed, purely technical ability may be only the foundation for a comprehensive package of aesthetic faculty excellences. A competent flautist, for example - with faculty prowess that characterises good playing - can perform well in the sense that she is able to satisfy the demands set by a range of musical pieces. But there is a further range of ways in which excellence as a flautist may be manifested, and these go beyond mere technical prowess. She may be, for example, a passionate musician, or an imaginative performer, or a clever player. Similarly, a competent painter may have aptitudes such as an eye for colour and a steady hand, and thus be able to produce technically accomplished canvasses. But these abilities do not exhaust the ways in which she can be a good painter. On top of them, she may for example be witty, or insightful, or sensitive in her painterly capacity. Although the term doesn't fit perfectly with our everyday usage, we can - following Jason Baehr's (2011) taxonomy of the intellectual virtues - label these forms of aesthetic ability talents, to be understood as "localized enhancements or excellences of faculties" (2011: 25, emphasis in original). ${ }^{2}$ Aesthetic talents are powers to bring special, positive qualities to one's artmaking; the kinds of quality that mark one out as more than just technically adept in some artistic sphere. The talents, moreover, are not simply behavioural competences, but are tied closely to intellectual and discriminative powers. To be an imaginative painter requires one to have good powers of visual imagery, for instance, while being a witty writer requires that one can determine what is funny and capture it in one's prose.

Several key properties of the aesthetic faculty virtues mark them out from the trait virtues. First, although faculty virtues may have been acquired and enhanced over time through practice and experience, they need not have been. Some aesthetic competences simply come naturally to the artist, such as the capacity of perfect pitch, or an innate sense of rhythm. This is true of talents, too. Although wittiness, cleverness, or imaginativeness may not be present from birth, they can be in someone's nature, rather

\footnotetext{
2 In the epistemic case, talents include insightfulness, imagination, and lateral thinking power - the kinds of ability we associate with intelligence.
} 
than being the product of self-conscious cultivation. Faculty excellences are not available to everyone, even with practice. Many people lack natural artistic endowments - they are not gifted with a fine voice or good rhythm, for example - and it is rare to find a person who excels in more than a few artistic disciplines, either as performer or critic. It follows that, as with the case of epistemic faculty virtues such as sensory or mnemonic prowess that also fall outside an agent's voluntary control, these need not be properties for which the agent deserves special credit or blame. A person is not to be criticised for her inability to paint a stunning landscape, or to perform some challenging musical piece, when this failure is no fault of her own.

Secondly, an agent's aesthetic faculty excellences bear no necessary connection to her motivational or affective states. Just as an epistemic subject can reach the truth by exercising her reliable faculties even when she doesn't care about knowledge, so an artist or performer can possess great technical expertise and talent but have little concern for these qualities or their outputs. A musician whose skills are the result of a punishing training regime in childhood, for example, may lack any desire to play the instrument, and take little pleasure in doing so. Furthermore, the possession of skill and talent is compatible with being driven by any of a range of motives, vicious or virtuous. Wit or imagination can be deployed in ways that exhibit cruelty, contempt, or spite, for example, while a greedy or cowardly artist can nonetheless perform with great technical facility.

\subsection{Two kinds of aesthetic virtue?}

Two clarificatory questions must be addressed at this juncture. Are the so-called faculty virtues really virtues proper, and does the conceptual distinction between trait and faculty excellence really map onto a difference in kinds of aesthetic virtue. Existing work in virtue aesthetics has answered the first question in the negative, presenting the aesthetic trait virtues as having a distinctive status over and above mere artistic skill and technical facility (e.g. Goldie 2007:382). I argue, in contrast, that any complete account of aesthetic virtue must make essential reference to the faculties of the agent, and that - to answer the second question - it is not always possible to fully specify the trait virtues without appeal to corresponding faculty virtues. However, if we are to understand the core project of virtue aesthetics to be that of characterising what it is for an agent to be an exemplar of aesthetic excellence, then abilities and talents of execution and performance 
are likely to loom large whether we call them 'virtues' or not. If we choose to restrict 'virtue' to traits of character articulated along Aristotelian lines, and to label qualities of execution 'faculty excellences' instead, then both will still contribute to a person-focused approach to aesthetics. Moreover, faculty virtues contribute to the value and significance of art, as we will see in the next section.

Aesthetic trait and faculty virtues are not fully separable: there are three kinds of dependency that hold between them. Firstly, certain aesthetic trait virtues are not appropriately attributed to an agent unless she is equipped with suitable faculty prowess. Consider the portrait painter again. This artist's trait of honesty depends upon her ability to capture her sitter's likeness through the exercise of her aesthetic faculties - her accuracy as a draftsperson, her use of colour and light, and so forth. Merely being moved by a concern to faithfully reflect the sitter in her art counts for little if she hasn't the skill to realise this ambition. Similarly, a songwriter's committed pursuit of melodic novelty is a virtue only insofar as she is genuinely capable of composing music that has a degree of originality. These cases imply that there is not always a strict separation between the trait and faculty virtues; rather, the latter are sometimes necessary for the former, as the traits are partly constituted by qualities of execution as well as by their motivational profiles.

Secondly, the dependency runs the other way in certain cases. That is, the acquisition and manifestation of aesthetic faculty excellence can require that the agent have particular virtuous character traits. To be an accomplished sculptor in a medium such as marble surely demands patience and determination, both in the development of technique and in the execution of a piece over a lengthy timescale. Likewise, ballet performance calls for persistence and enthusiasm; large-scale visual art entails ambition, and so forth.

Thirdly, there are trait virtues that must be characterised in terms of an agent's sensitivity to her own aesthetic skills and abilities. Consider an aesthetically conscientious singer; that is, one who has a dominant concern for the aesthetically good, and suitable states of motivation and affect that characterise this evaluative stance. But now imagine that she consistently overestimates her own vocal range and ability, and that this mistaken selfevaluation has the effect that she is excessively willing to perform in public when the opportunity arises, to the audience's dismay. Or take, in contrast, a writer who is too modest about her own powers, such that she is reluctant to partake in the creative 
process, or to reveal her work to a readership. This individual, although she too may be motivated to pursue the aesthetically good, fails to do so to the best of her ability. These cases indicate that part of being a fully virtuous aesthetic agent is having a suitable appreciation of one's own faculty-level aptitude, in order to evaluate how one is best able to pursue the aesthetic goods that are the objects of one's conscientious attitudes. The over-enthusiastic singer and the self-effacing writer both have aesthetic deficiencies that are the result of failing to properly acknowledge the extent of their own talents and abilities. Someone who accurately appraises her own strengths and weaknesses as an artist, meanwhile, not only gains a sense of the circumstances under which it is appropriate for her to exercise her talents, but is also able to engage in self-improvement through practice and training where necessary (and so to exhibit virtues of persistence and fortitude). Part of what it is to be aesthetically conscientious - to be fully traitvirtuous - is thus that one be prepared to keep track of one's faculty qualities, and to deploy them appropriately in the pursuit of aesthetic goods.

\section{Virtue and the Value of Art}

The distinction between aesthetic trait and faculty virtues allows us to understand more fully the many varieties of value that accrue to works of art. Attending to the faculty virtues encourages us to understand the virtuous production of art as a kind of achievement that is creditable to an agent, and which sees artworks as thus accruing a familiar kind of value that is common to agential successes in general. Attending to the trait virtues highlights the additional value that accrues to outcomes that are appropriately related to virtuous motives, and thus aligns aesthetic activity more closely with the traditional virtue-theoretic conception of moral conduct. In drawing these values out, I do not follow Lopes in arguing that the virtues inherit their value from the intrinsic value of art, nor do I follow Goldie in arguing that the value of art comes from its instrumental role in enabling emotional sharing. Both achievement value and motivational value are species of final value, determined by the relational properties of an entity rather than its intrinsic features, in this case by the connection it bears to the qualities of the agent who produced it.

Again, both ways of conceiving of the relation between the exercise of virtue and the value of the products of virtuous activity have a precedent in the epistemology literature, 
where the challenge is to account for the additional value that states of knowledge have, over and above the value of mere true belief (the Meno Problem, or Primary Value Problem, e.g. Pritchard 2007). Epistemic virtue reliabilists treat true beliefs that constitute intellectual achievements as more valuable than those that are not attributable to the exercise of the agent's faculty virtues (e.g. Greco 2003, 2009; Riggs 2009); while epistemic virtue responsibilists model the value of knowledge on that of well-motivated moral behaviour (e.g. Zagzebski 1996).

\subsection{Achievement value}

Virtue reliabilists appeal to the strong intuition that there is something special about successes that are achievements creditable to an agent. A sprinter whose victory is the result of her being the fastest runner on the field is to be valued more highly than one that is due to the rest of the competitors falling over at the starting line (Pritchard 2010:19); an archery bullseye is better when it is the product of the sportsperson's unerring skill than when the arrow was caught by a fortuitous gust of wind (Sosa 2007:28-19). Intellectual successes such as the formation of true beliefs, similarly, accrue greater value when they are cognitive achievements rather than mere lucky outcomes. That is, when an agent's true belief issues from the exercise of her own epistemic powers, it acquires both the status of knowledge and the additional value that comes with this status. ${ }^{3}$

A catalogue of familiar examples support the parallel proposal that aesthetic achievements are to be valued more highly than otherwise-similar outcomes that lack an essential connection to the skills and attributes of the agent. Consider our opinion of an operatic performance that appears initially to embody an exceptional vocal range and tonal purity, and how our evaluation of the singing changes when we learn that the performance has been enhanced artificially with auto-tuning technology (see, e.g., Dutton 1979). We would have a similar evaluative reaction to a hyper-realistic portrait upon learning that it had been traced from a photograph, to an elaborate piano riff upon discovering that it had been sped-up post-recording, or to an apparently off-the-cuff quip upon revealing that it had been scripted and rehearsed.

\footnotetext{
${ }^{3}$ In Gettier cases, in contrast, the acquisition of a true belief proceeds by lucky or accidental means, and so the virtue reliabilist has an explanation of why it is appropriate to deny such beliefs the status and value of knowledge.
} 
We care not only about the finished artistic product in cases such as these, but about how it came into being: its status as the fruit of someone's aesthetic labour - the output of abilities, expertise, and talents put into practice by the skilled agent. How the work was executed matters to our evaluation - we value those art objects and performances that constitute achievements, and disfavour those that lack an appropriate connection to the individual's agential powers. If a spilled paint pot yields a simulacrum of an abstract expressionist piece, we may enjoy the image and the coincidence, but it ought not to be treated - and esteemed - as an artist's skillful accomplishment.

For an achievement to be creditable to an individual, that person's abilities must figure prominently in the causal explanation of how and why the success was attained (see, e.g. Pritchard 2012 for discussion). For an archery achievement, the agent's various skills as an athlete - her strength and posture, the steadiness of her hand and eye, and so forth must be the salient contributors to the arrow's flight to the bullseye. For a doxastic achievement, the acquisition of a true belief must be explained by reference to the subject's cognitive powers, such as her sensory capacities and reasoning skills. Aesthetic achievements, too, are those such that any comprehensive explanation of why the artwork is the way that it is must advert to the artist's exercise of her aesthetic faculty virtues. If, instead, the perceptible features of a work are best explained in terms of competing factors that lie outside of the agent's capabilities - circumstances of luck or accident; the intervention of another person; or the deployment of automating technologies ${ }^{4}$ - then we are inclined to think that these undermine the extent to which those features constitute a success that is creditable to the individual herself.

The degree to which some outcome counts as an achievement - as we might say, how impressive it is - can vary according to who the protagonist is, and the context in which she is housed. Scoring an archery bullseye on a very wide target over a short distance will constitute a greater achievement for, say, the young or inexperienced archer than for the expert. A particular completion time in a distance-running event may constitute a greater achievement in the Paralympic than in the Olympic games. In the aesthetic domain, too, a given outcome (an image, a musical performance, a dance move) can be more or less impressive depending on who its creator is. We reserve special praise for the one-handed

\footnotetext{
4 As Dutton (1979) notes, there may well be cases in which an artist's expertise with a tool or technology permits her to achieve music or visual results of which she would otherwise be incapable, and in doing so enjoy a success that is still rightly attributed to ber.
} 
piano playing of Paul Wittgenstein, for instance, or for the late-career paintings of Monet, whose cataracts led to deteriorating vision.

These considerations lend support to a two-factor analysis of achievement (Pritchard 2010). Achievements are successes that involve conquering some challenge, and/or that require a rare, uncommonly high degree of skill. The challenge or obstacle to be overcome may simply be constituted by the effort and investment that it takes to acquire a particular ability, such as technical proficiency with a musical instrument, or it may be an individual impediment determined by one's physical makeup or one's historical and cultural environment. For example, the performance of a self-taught musician may be a greater achievement than a similar display by somebody who has enjoyed a long and well-supported training history. More widely, it is a special achievement to be at the very forefront of a new movement in some artistic domain - for instance, to write the very first rock and roll songs, or to develop a style of painting - and less of an achievement to continue to produce similar pieces once a body of existing work is in place.

Sometimes, secondly, a fine achievement is simply the result of the exercise of a high degree of skill; it is the kind of rare feat that only an exalted few are capable of performing. Tiger Woods's putts are not, for him, difficult accomplishments or conquerings of an obstacle (Pritchard 2010: 23-24), but they are achievements in virtue of requiring a great deal of skill and expertise. The effortless sounding music-making of a virtuoso string player, similarly, or the highly graceful motions of a prima ballerina fall into this bracket. They are outliers on the scale of skilled performance; successes that we prize highly for their exceptional, superlative nature.

The value that something has in its capacity as an achievement is thus not exhausted or explained by its intrinsic value. It is a form of final value the understanding of which necessitates essential reference to qualities and powers of individual persons. If it is a defining theme of a virtue-theoretic approach to aesthetics that attributes of persons ought to figure into our evaluative practises, then conceiving of artworks as accomplishments of the aesthetic faculty virtues is one way to secure this. Artworks and performances can, in addition to exemplifying aesthetic goods such as beauty, wit, and elegance, be impressive human achievements; sometimes at the upper limit of human 
ability, sometimes when they exemplify hard-won or exceptional technical skill, and sometimes as triumphs over adverse conditions.

\subsection{Motivation value}

How might an agent's trait virtues - those features of her character that reflect an overarching concern for aesthetic goods such as beauty and novelty - be related to the value and significance of art? The position developed by Lopes (2008) is that virtuous traits inherit a species of intrinsic value from the artworks towards which they are oriented. Lopes takes up G.E. Moore's proposal that pro-attitudes towards things with intrinsic value are themselves intrinsically valuable (Moore 1903). If X is good, in and of itself, then it is good to care for X, to desire $\mathrm{X}$, to think highly of $\mathrm{X}$, to hope for $\mathrm{X}$, and so forth. If beauty is intrinsically good, then it is intrinsically good to have, cultivate, and exercise pro-attitudes towards beauty, including the profiles of concern and motivation that characterise the aesthetic trait virtues. This approach, which emphasises how traits of character might accrue value in virtue of their relation to some aesthetic good, leaves open the question of whether the reverse is also true; that is, whether an artwork can gain value through its relation to the qualities of its creator's character. I suggest that it can.

The problem is to understand how features that belong to an individual - how she thinks and feels; what she cares about; what she is motivated to do - might contribute to the value of the things that she produces, given that the latter are distinct from, and external to, her. Why should an object whose creation was motivated by a particular concern be any better or worse than one that lacks this connection to the internal state of the agent? In the epistemic case, the virtue responsibilist faces the equivalent question of how an agent's cognitive character might contribute to the value of a belief. The Meno problem, from this perspective, concerns how to explain the differential value possessed by true beliefs that are the products of intellectually virtuous traits such as open-mindedness, humility, and freedom from bias. In what sense might well-motivated, virtuous doxastic states be better than poorly-motivated ones?

Linda Zagzebski (2003:15) offers the analogy of a coffee machine that produces espresso. The goodness of the espresso is surely not determined by the qualities of the machine of which it is an output (for instance, by its reliability), but by the features it has 
in and of itself - its tastiness, richness, hotness and so forth. The challenge for epistemology is thus to understand how and why doxastic states should be better or worse depending on the qualities of the person who has them (for instance, her reliability in coming to have true beliefs), when machine-products, as a rule, don't accrue value from the machines that produce them. Zagzebski's solution draws upon the familiar virtue-theoretic thought that actions can have greater or lesser value depending on the motivations that drive them. A donation to a charitable cause, for example, is more morally admirable when it is performed out of compassion and concern for the needy than when the agent had a selfish wish to look good in front of her peers. Even actions that fail to achieve some desirable moral goal can accrue value when they flow from an estimable motivation, such as when an individual makes an unsuccessful attempt at a heroic rescue.

Actions are thus not related to their author merely as a product is related to a machine; they can instead express or manifest that author's agency, and can thus inherit qualities of her character. Both actions and agents can be humble, courageous, and kind; or greedy, cowardly, and selfish. To transfer this lesson to the epistemic case, Zagzebski develops an action-like conception of belief, according to which the primary targets of epistemic evaluation are acts of believing or judging that the agent performs, rather than stored doxastic states. Thought of in this way, believings can be seen to bear the same sort of close relationship to motivation that ordinary, overt actions enjoy. Well motivated acts of judging can have admirable qualities; they can be epistemically fair, for example, or intellectually honest. Virtuous true believings, although they may have the same intrinsic and instrumental value as any other element of a subject's doxastic condition, thus possess additional value through their connection to traits of the believer's character.

In the aesthetic domain, there is a clear category of cases for which a parallel account can be given, and which demonstrates the contribution that a virtuous character can make to the value of a work of art. The clearest members of this class consist of artworks that are themselves performances - actions that can gain motivational value in just the same way as moral behaviours such as acts of charity or kindness. Acts of dancing or musical performance, for example, are episodes in which an agent carries out some complex array of actions that can be, or fail to be, governed by high-quality motivations. When an instance of dancing is motivated by a love of beauty (or of elegance, or gracefulness), it is 
reasonable to prefer it to an otherwise identical behavioural episode that is not grounded in such a motivation - for instance, one that is driven primarily by a desire for prestige or riches. As with moral and epistemic behaviour, well-motivated aesthetic actions can be appropriately described using the language of individual virtues: a vocal performance can be honest; a violin recital can be ambitious, and so forth. In contrast, poorly-motivated aesthetic acts can themselves be vicious; for instance the hogging of the limelight by a vain actor, or a rock guitarist's self-indulgently long solo.

Where the object of our aesthetic evaluation is an action (or suite of actions), then, it is intelligible to appeal to the contribution of the motivational aspect of an agent's character traits in establishing the value of that action. Virtuous actions that are motivated by a love of the aesthetically good are to be preferred to those that are not, just as we prefer actions performed out of a love of the morally good, or judgings that reflect a love of the truth. A virtuous act of artistic performance is not simply a causal product of its author's activity, separable from her agency and the quality of her motives. It can take on her admirable (or contemptible) evaluative properties, and so accrue value over and above that which is determined by its intrinsic features. It is by emphasising the action-involving nature of this class of artworks, then, that the virtue-theoretic approach is able to most closely align them with an existing model of moral and epistemic conduct.

Many artworks, however, are plausibly conceived of not as actions, but as the static products of an individual's artistic activity. ${ }^{5} \mathrm{~A}$ painting is not itself an action or suite of actions, and nor is a poem, a novel, or a sculpture. All are the final output of an agent's creative endeavour; they are not identical to that endeavour, as dancing or singing may be. For examples such as these, the 'machine product' challenge is evident: why should entities that are distinct from and external to an individual be thought to accrue any special evaluative significance from the quality of that individual's character? Even if a given act of painting or sculpting reflects admirable motivations, for example, it is a further question as to whether this motivational value attaches also to the finished products of that virtuous creative activity.

\footnotetext{
${ }^{5}$ It should be noted here that there are ontologies of art that take it to be a general truth that works of art are to be identified not with material objects, but rather with actions. For example, with token acts of articulating a particular artistic content (Davies 2004, 2005), or with action-types in which an artist arrives at a certain pattern or structure, such as an arrangement of musical sounds or brushstrokes (Currie 1989). Such views are apt to avoid Zagzebski's 'machine product' challenge, but are not uncontroversial (see, e.g., Levinson 1992; Matravers 2005; Matheson \& Caplan 2008). Thanks to an anonymous reviewer for highlighting these alternatives.
} 
I propose that art objects can inherit the virtuous or vicious qualities of its creator, when they embody, express, or reveal traits of her character. That is, there are some works of art that stand in a relation to their author, and her cares, concerns, and motivations, that is closer than that which a machine product bears to its producer. When a virtue is manifested in a work in one of these ways, it is appropriate to evaluate it on this basis, as an object that is the product not only of an individual's skilled agency, but as something shaped and crafted according to what she cares about.

Consider, firstly, that many works of art are designed to perform a communicative act: to express an opinion or emotion, to make a protest or promote a manifesto, to confess, to give thanks or pay tribute, and so forth. ${ }^{6}$ That is, they are not simply static objects with arrangements of perceptible properties; they are vehicles of the artist's agency - they carry and convey her messages; divulge her inner feelings; set out her stall on matters of importance. In this way, the artist's cares and concerns are revealed in the work, and something of her character is open for public observation. When we read a confessional poem, we learn of its author's aesthetic courage and honesty - her willingness to expose her most private thoughts and feelings to her audience for the sake of her art - and thus of the aesthetic virtues she brought to bear in the work. As Dutton puts it: "works of art represent the ways in which artists solve problems, overcome obstacles, make do with available materials... the work of art has a human origin, and must be understood as such" (1979: 24). In cases like the confessional poem, we can see that the work must be understood not only as the product of a human's skilled activity, but as something that reflects what she cares about, and what she intends for the work to do. The challenges and obstacles faced by the agent in the process of creation are not only technical hurdles (the ones to be overcome by excellences of artistic execution) but tests of character. The object is the way that it is, in this case, because the agent has committed to making certain personal revelations, to opening herself up to critical eyes, and to setting aside concerns of privacy and vanity for the sake of the art work.

Secondly, the expressive properties of an artwork can embody an agent's virtues. A painted image, for example, that is richly expressive can disclose the artist's dedication to the work: that she has put so much of herself into the painting is visible in the way that it expresses her anger, or her grief, say. Here, the painter's aesthetically conscientious

${ }^{6}$ See Maitland 1975: 192 for discussion. 
attitude - that is, her overarching concern for the promotion of beauty - comes over in the expressive character of the work. Moreover, when the piece reveals her own deeply held cares and interests, it may again be suitably described as an honest work, or a work with integrity. Conversely, a work that is expressively flat and unemotional may reflect a lack of concern on the artist's part - a failure to invest in the work in question, motivationally.

Thirdly, the structural features of a work of art - that is, the ways in which it is put together, including its various formal, non-representational properties - can embody virtues and vices. A novel with an experimental narrative structure, for example, may be bold in its refusal to conform to convention, while one that does the opposite may be lazy. The same goes for the sculptor's use of materials; the painter's colours; the composer's decisions on the dynamics of a piece; and so forth - in each case, the features of the medium (broadly speaking), as much as the content and expressiveness of the work, can reflect what matters to the artist, and the choices she has made in the course of making the art object. Vices of the artist, too, can show up in the structural properties of a work: a writer's vanity can be visible in her prose's overwrought complexity, which reveals an immodest desire to impress, for instance.

In such scenarios, any comprehensive explanation of the why the artwork has the properties that it does must advert to features of the artist's character and motivations. Why is this song's tune so similar to the artist's previous, profitable work? Because it was motivated by a desire for continued popularity and income, rather than by a love of novelty and melodic excellence. Why does this text have its peculiar, experimental structure? Because the author had courage, and a dedication to her craft. It is possible to learn about the agent's motivations by perceiving her artwork, and it is possible to learn about the qualities of the artwork by knowing the agent's motivations. We can see the writer's apathy in the sloppy character of her prose, for example, and the painter's honesty in her faithful depiction of her portrait sitter. This access is not infallible, however - we can go wrong in attributing motivational qualities to a work on the basis of its perceptible features. The experimental structure of the novel may turn out to have been an artefact of a printing error; the passionate brush-strokes entirely accidental; and so forth. Similarly, discovering that an artist's motivations were not as they seem can alter our evaluation of the artwork. Our opinion of an intimate, heartfelt ballad, for instance, 
changes when we learn that it was written by a cynical team of music executives, for this forces us to rethink what the work does - it can no longer be properly thought of as a sincere, courageous disclosure of an individual's private thoughts and feelings. Once again, these evaluative changes indicate that we tend to approach artistic outputs with the implicit assumption that they constitute manifestations of their creator's virtues. Firstly as products of her skills and abilities as an artist, and secondly as objects in which the artist has invested time, effort, and concern, and that express or reveal her commitments and values.

We now have on the table four possible sources of value that emerge from the analysis of the relation between an agent's aesthetic virtues and the artworks with which she is associated. There is the eudaimonic value that accrues to the virtues through their connection to practises of emotional sharing (Goldie); the intrinsic value that accrues to the virtues through their constituting pro-attitudes towards intrinsic aesthetic goods (Lopes); the achievement value that accrues to artworks through their connection to the agent's faculty excellences; and the motivational value that accrues to artworks due to their authors' love of the aesthetically good. All four are capable of coming apart: we can have artworks that are well motivated but poorly crafted and which afford little emotional engagement; skilful artistic achievements performed by an agent who cares little for beauty; and so forth. These distinctions reflect that the question of why art matters to us permits, from the point of view of a virtue theory of art, a variety of answers. Sometimes, art matters insofar as it affords a shared emotional response; sometimes it matters insofar as it represents an achievement at the outer limit of an individual's ability; sometimes it matters insofar as it discloses an agent's character; sometimes it matters for its intrinsic properties.

\section{Conclusions}

The virtue-theoretic approach to aesthetics encourages us to attend to the qualities and characteristics of authors and appreciators of works of art, and to understand the value and significance of those works as flowing, in part, from an individual's virtues and vices. In common with debates over how best to characterise the intellectual virtues, we have seen that there are two non-identical ways of circumscribing distinctively aesthetic forms of virtue. We can treat them as deep and abiding traits of an agent's character, reflecting 
an enduring concern for the aesthetically good that permeates her creative and appreciative activity, or as a profile of skills and talents that enable her to realise her artistic aims. The aesthetic vices, in turn, may involve a failure to properly care for aesthetic goods such as beauty, novelty, or expressive power; or they may lie at the level of execution, and constitute a lack of precision, dexterity, gracefulness and so forth.

Any full characterisation of aesthetic virtue ought to appeal to both of these categories in specifying what it is for a person to be aesthetically excellent; not least because they are not always strictly separable. Without a regulative grip upon her own skills and abilities, and their limits, an agent cannot fully instantiate trait virtues such as aesthetic honesty, ambition, and humility. And there are virtues of artistic execution that require particular traits of character in order to be acquired or instantiated, such as the patience to become a brilliant pianist, or the determination and ambition involved in sculpting in marble. It is not possible, then, to hive off excellent aesthetic character traits as especially deserving of the 'virtue' label, even given their proximity to traditional Aristotelian categories, because they are too intimately bound up with qualities of the aesthetic faculties.

The distinction in kinds of aesthetic virtue can be put to philosophical work, moreover, in permitting us to isolate and explain two of the forms of value that accrue to art objects and performances in their capacity as outputs of virtuous agency. Virtues of execution yield achievements that are creditable to their authors - personal successes that overcome obstacles and represent triumphs of human ability. Artworks that are the products of virtues of aesthetic character express, reflect, or embody high-quality motives - they are driven by a concern for the aesthetically good - and so sit alongside moral and intellectual actions in accruing value from the agent's virtuous internal condition.

\section{References}

Axtell, G. (1997), 'Recent Work in Virtue Epistemology', American Philosophical Quarterly, $34: 1-27$ 
Baehr, J. (2011), The Inquiring Mind: On Intellectual Virtues and Virtue Epistemology, Oxford: Oxford University Press

Battaly, H. (2008), 'Virtue Epistemology', Philosophy Compass, 3:639-663

Code, L. (1987), Epistemic Responsibility, Hanover, NH: University Press of New England

Currie, G. (1989), An Ontology of Art, Palgrave Macmillan

Davies, D. (2004), Art as Performance, Oxford: Blackwell

Davies, D. (2005), 'Reperforming and Reforming Art as Performance: Responses', Acta Analytica, 20(4):64-90

Dutton, D. (1979), 'Artistic Crimes: The Problem of Forgery in the Arts', British Journal of Aesthetics, 19(4):302-314

Goldie, P. (2007), 'Towards a Virtue Theory of Art', British Journal of Aesthetics, 47(4):372387

Goldie, P. (2008), 'Virtues of Art and Human Well-Being', Proceedings of the Aristotelian Society Supplement 82:179-195

Goldie, P. (2010), 'Virtues of Art', Philosophy Compass, 5(10):830-839

Greco, J. (2000), 'Two Kinds of Intellectual Virtue', Philosophy and Phenomenological Research, 60(1):179-184

Greco, J. (2003), 'Knowledge as Credit for True Belief, in Intellectual Virtue: Perspectives from Ethics and Epistemology, M. DePaul \& L. Zagzebski (eds), Oxford: Oxford University Press

Greco, J. (2009), 'Knowledge and Success from Ability’, Philosophical Studies, 142(1):17-26 
Greco, J. (2012), 'A (Different) Virtue Epistemology', Philosophy and Phenomenological Research, 85(1):1-26

Huddleston, A. (2012), 'In Defense of Artistic Value', Philosophical Quarterly, 62(249):705714

Kieran, M. (2010), 'The Vice of Snobbery: Aesthetic Knowledge, Justification and Virtue in Art Appreciation', Philosophical Quarterly, 60(239):243-263

Kieran, M. (2012), 'For the Love of Art: Artistic Values and Appreciative Virtue', Royal Institute of Philosophy Supplement, 71:13-31

Levinson, J. (1992), 'Critical Notice of Gregory Currie’s An Ontology of Art', Philosophy and Phenomenological Research, 52(1):215-222

Lopes, D.M. (2008), 'Virtues of Art: Good Taste', Proceedings of the Aristotelian Society Supplement 82:197-211

Maitland, J. (1975), 'Identity, Ontology, and the Work of Art', Southwestern Journal of Philosophy, 6(3):181-196

Matheson, C. \& Caplan, B. (2008), 'Modality, Individuation, and the Ontology of Art', Canadian Journal of Philosophy, 38(4):491-517

Matravers, D. (2005), 'Two Comments and a Problem for David Davies' Performance Theory', Acta Analytica, 20(4):32-40

Montmarquet, J. (1993), Epistemic Virtue and Doxastic Responsibility, Lanham, MD: Rowman \& Littlefield

Moore, G.E. (1903), Principia Ethica, Cambridge: Cambridge University Press

Pritchard, D. (2007), 'Recent Work on Epistemic Value', American Philosophical Quarterly, 44(2):85-110 
Pritchard, D. (2010), 'Achievements, Luck and Value', Think, 9(25):19-30

Pritchard, D. (2012), 'Anti-Luck Epistemology', Journal of Philosophy, 109(3):247-279

Riggs, W. (2009), 'Two Problems of Easy Credit', Synthese, 169:201-216

Smith, A.M. (2005), 'Responsibility for Attitudes: Activity and Passivity in Mental Life', Ethics, 115:236-271

Sosa, E. (1991), Knowledge in Perspective, Cambridge: Cambridge University Press

Sosa, E. (2007), A Virtue Epistemology: Apt Belief and Reflective Knowledge, Volume I, Oxford: Oxford University Press

Woodruff, D.M. (2001), 'A Virtue Theory of Aesthetics', The Journal of Aesthetic Education, $35(3): 23-36$

Zagzebski, L. (1996), Virtues of the Mind: An Enquiry into the Nature of Virtue and the Ethical Foundations of Knowledge, Cambridge: Cambridge University Press

Zagzebski, L. (2008), 'The Search for the Source of Epistemic Good', Metaphilosophy, $34(1 / 2): 12-28$ 